ISSN 2638-4914

Volume 1, Issue 2, 2018, PP: 20-24

\title{
Low Level Laser Treatment for Patterned Hair Loss: A Systematic Review
}

\section{Omeed Memar ${ }^{1 *}$, Benjamin Caughlin ${ }^{2}$, Hamid Djalilian $^{3}$}

${ }^{1}$ Academic Dermatology \& Skin Cancer Institute, Chicago, Illinois

${ }^{2}$ Department of Surgery / Division of Otolaryngology, John H. Stroger, Jr. Hospital of Cook County, Chicago, Illinois. Division of Facial Plastic and Reconstructive Surgery, Jesse Brown VAMC, Chicago, Illinois. Division of Facial Plastic and Reconstructive Surgery, University of Illinois Health Hospital System, Chicago, IL. Kovak Cosmetic Center, Oakbrook Terrace, Illinois.

${ }^{3}$ Professor Neurotology and Skull Base Surgery, Department of Otolaryngology Head and Neck Surgery, Irvine.

Orange, California.

omeedmemar@gmail.com

*Corresponding Author: Omeed Memar, Academic Dermatology and Skin Cancer Institute, 130 N. Garland Ct, Chicago, IL 60602. USA.

\begin{abstract}
Low level laser therapy (LLLT) uses a monochromatic and coherent beam in the red or near infrared wavelength. We asked whether the literature supports the effectiveness of LLLT for androgenic and female patter hair loss? The logic behind the use of LLLT comes from observation of paradoxical hypertrichosis while attempting laser hair removal, especially in skin of color. The mechanism of this is unknown. Weconducted a systematic review of the literature on the topic of LLLT and phototherapy for hairgrowth. The overwhelming results show that light in the red spectrum is effective in hair growth, but larger case-controlled studies are required to back up this conclusion.
\end{abstract}

Keywords: Low level laser treatment, male pattern hairloss, female pattern hair loss, paradoxical hypertrichosis, photobiomodulation, alopecia, LLLT, cold laser.

\section{INTRODUCTION}

Male pattern androgenetic alopecia (AAl) and female pattern hair loss (FPHL) are chronic conditions which causes social and psychological distress. In AAl hair recedes bilaterally from the anterior to posterior scalp and the vertex, while in FHPL hair thins diffusely on the entire crown and then sides without anterior receding. ${ }^{1}$ Thirty percent of 30 year old white males have some degree of androgenetic hair loss, and same by age $50,50 \%$ had $\mathrm{AAl}^{2}$ Birch et alfound that $38 \%$ of women who are 70 years of age and older develop some degree of female pattern hair loss; while only $6 \%$ of those under the age of 50 develop female pattern hair loss. ${ }^{3}$ Both AAl and FPHL show non-scarring follicular miniaturization clinically and histologically. ${ }^{1}$ In male pattern hair loss, dihydro testosterone (DHT) is associated with miniaturization of regrowing hairs. The etiology of FPHL is in part associated with decreasing free estrogen levels and possibly end organ receptor affinity. Three different genes have been associated with FPHL, Ectodysplasin A2 Receptor (EDA2R), Androgen Receptor (AR), Aromatase CYP19A1. ${ }^{4}$

Pharmacologic options are limited for AAl and FPHL. There are currently two FDA approved drugs for AAl (topical minoxidil and 5 alpha reductase type 2 inhibitors) and one FDA approved treatment for FPHL (topical minoxidil). However, there are other treatments used for both conditions. One nonpharmacologic therapy is light based therapies. Here, we will review the literature on LLLT and hair growth.

\section{METHODS}

\section{Literature Search}

A systematic review of the literature was performed to gather information on reports and studies on LLLT and effect on hair growth up until November 2018. 
Low Level Laser Treatment for Patterned Hair Loss: Is it Effective?

Inclusion criteria was meta-analyses, systematic reviews, and case-controlled studies. Smaller studies were included, but given lower power. The database of Ovid Medline and Google Scholar were searched using the Boolean string: (hair AND low-level laser therapy). In addition, the references cited in the articles were reviewed for any additional reporting.

\section{Introduction}

The F.D.A. classifies low-level lasers as class 3A, and do not have the fluence to damage cells. Huang YY et al described the low-level laser therapy as 600-1000nm wavelength spectrum red or near-infrared light with fluence (energy density, commonly referred as "the dose of laser") between 1-20 J/ $\mathrm{cm}^{2}$ and irradiance (power density) 5-50 mW/ $\mathrm{cm}^{2} .5$ Another description for LLLT by Jimenez et alis $500-1100 \mathrm{~nm}$ in wavelength and $1-4 \mathrm{~J} / \mathrm{cm}^{2}$ in fluence with a power density of 3-90 $\mathrm{mW} / \mathrm{cm}^{2.6}$

Clinical use of low-level laser therapy was first introduced by Hungarian physician EndreMester in 1967. ${ }^{7}$ Mester noticed that HeNe laser induced tissue repair and hair growth in mice. Later therapeutic usages of LLLT (also named as photo biomodulation) were extended to 'wound healing, analgesic action on joint pains due to arthritis and anti-inflammatory action. $^{7}$

Laser fluence was optimized with description of selective photo thermolysis by Anderson et alin $1983 .{ }^{8}$ Selective laser hair removal was shown by Grossman et alin $1996 .{ }^{9}$ Some of the patients undergoing laser hair removal developed hypertrichosis characterized by coarse and dense hair in the treatment area and adjacent areas. First report of paradoxical hypertrichosis was by Moreno-Arias et al in 2002.10

Paradoxical hypertricosis is seen in a number of laser and light based systems, meant for laser hair removal, including the ruby laser, diode laser, alexandrite laser, Nd:YAG (neodymium : yttrium - aluminum-garnet) laser, IPL (Intense Pulse Light) devices. ${ }^{11}$ Among these different systems, paradoxical hypertrichosis is most commonly seen with IPL ${ }^{11}$ which has wavelengths between 515-1200 nm. A clinical trial done by Bedewi et al on 210 patients showed 1\% hypertrichosis rate after 3-5 sessions of IPL treatment at 6 week intervals. ${ }^{12}$ Moreno-Arias et al showed that $10.2 \%$ of study patients experienced hypertrichosis after IPL treatment for facial hypertrichosis and found out that all patients with this side effect had polycystic ovarian syndrome. ${ }^{10}$ It is reported that paradoxical hypertrichosis is more common in patients with dark skin tone and dark-thick hair. ${ }^{13}$ Alajlan et al reported a $0.6 \%$ rate with the long pulsed alexandrite laser (755 nm); all patients with this side effect had skin phototype 4 and black hair. ${ }^{14}$

Several hypotheses are under scrutiny about the paradoxical hypertrichosis effect of laser treatment. In laser hair removal, the target structure is melanin in the hair shaft and germinative layers of the follicle. ${ }^{11}$

According to study done by Levy V etal, epidermal stem cells arise from hair follicle undergo reprogramming and contribute to the wound healing after wounding. ${ }^{15}$ If we think of laser as a means of wounding, this might be contributing the hair growth in the treatment area. Kim et al reported hair growth in $\mathrm{C} 3 \mathrm{H} / \mathrm{HeN}$ mice, after using fractional $1550 \mathrm{~nm}$ wavelength fractional erbium glass laser to create microcoagulative wounds in the dermis, this triggered an induction in the Wnt/betacatenin growth pathway of hair follicle which occurs 24 hours after microcoagulative injury in the dermis (with using semi quantitative RT-PCR study, they showed that Wnt10 mRNA increased after fractional laser irradiation). ${ }^{16}$ They emphasized that frequent ( 2 times/week) laser treatments with increased energy levels may cause fibrotic changes around hair follicle; on the contrary to low level application of laser irradiation (with 2 weeks of intervals) which induced hair growth via Wnt/beta-catenin pathway and other speculated growth factors like VEGF, IGF, FGF and shifted hair follicle into anagen phase. ${ }^{16}$ Growth factors like VEGF also increase vascularization and blood supply to hair follicle.

Huang YY et al resembled effects low level laser therapy to photosynthesis in plants because of the enhanced mitochondrial respiratory chain activity after LLLT. ${ }^{5}$ Primary photo acceptor of the red and near infrared light in the cellular level is thought to be Cytochrome c oxidase of the respiratory electron transport chaincomplex $4 .^{5}$ In this way it is found that LLLT increases proton electrochemical potential, NADH synthesis, ATP synthesis, mitochondrial RNA and mitochondrial protein synthesis. ${ }^{17,18}$ Absorption of LLLT's photons by mitochondrial and membranal cytochromes, endogenous porphyrinsand flavoproteins trigger ROS generation and this in turn induces NF-kB which is a well-known transcription factor of genes that regulate cell proliferation. ${ }^{19}$ 
Low Level Laser Treatment for Patterned Hair Loss: Is it Effective?

Transcranial LLLT (wavelength $810 \mathrm{~nm}$ ) studies done on mice cortical neurons with traumatic brain injuries demonstrated an increase in mitochondrial membrane potential, ATP production and induction of NF-kB pathway at low fluences $\left(36 \mathrm{~J} / \mathrm{cm}^{2}\right)$ and low irradiances $\left(50 \mathrm{~mW} / \mathrm{cm}^{2}\right)$ of laser; on the contrary high fluences $\left(360 \mathrm{~J} / \mathrm{cm}^{2}\right)$ and high radiances $\left(500 \mathrm{~mW} / \mathrm{cm}^{2}\right)$ of laser reduced mitochondrial membrane potential, decreased ATP production and induced apoptosis by the cytochrome c release from mitochondria. ${ }^{5}$ This effect is named as biphasic dose response to LLLT. ${ }^{5}$

Another intracellular effect of LLLT is dissociation of NO from cytochrome oxidase. This dissociation enables cytochrome oxidase more active and thus ATP synthesis increases. ${ }^{20}$ It has been suggested that vasodilatory effect of LLLT is also related to NO release from nitrosyl heme proteins such as hemoglobin and myoglobin. ${ }^{21}$ Considering the short half-life of NO, this effect might be negligible in vasodilatation of follicular vascular bed.

The heat produced in the hair follicle by the LLLT may also induce Heat Shock Protein-27, a cell growth and differentiation regulator, thereby increasing follicular stem cell differentiation and growth without causing photo thermolysis in the hair follicle..$^{22}$

In 2005 Weiss et al, using RT-PCR,reported increase in potent hair follicle inducing proteins such as matrix metalloproteinase-2 (MMP-2), hepatocyte growth factor (HGF) and vascular endothelial growth factor (VEGF) gene expression of human dermal papilla cells after LED photo modulation. ${ }^{23}$

\section{RESULTS}

LLLT causes conversion of vellus and intermediate hair follicles to active follicles. Nevertheless, it also transforms dormant telogen follicles to anagen follicles. ${ }^{6} \mathrm{~A}$ systematic review of the literature in Google Scholar and PubMed concluded that LLLT is effective in stimulating hair growth in both men and women. ${ }^{24}$

Jimenez et al implemented HairMax Lasercomb and a sham device 8 to 15 minutes for 3 times a week, total 26 weeks on 146 male and 188 female subjects in a double blind randomized study. ${ }^{6}$ This study resulted in improvement of hair loss and thickness. ${ }^{6}$ Orasan et al used the HairMax in a controlled study, and showed when used with topical minoxidil, the hair density was greater with LLLT plus minoxidil than minoxidil alone in an animal model. ${ }^{25}$ Kim et alstudied $1550 \mathrm{~nm}$ $5 \mathrm{~mJ}$ fractional erbium laser on 20 Korean patients with MPHL in 5 sessions at 2 week intervals and also reported increase in hair density, growth rate, anagen/ telogen ratio; but they did not find an increase in hair thickness. ${ }^{16}$ An earlier study in 2003 by Satino et al on 28 male and 7 female patients with androgenetic alopecia reported increased hair count and tensile strength in both sexes with using HairMax Lasercomb for 5 to 10 minutes every dayover a 6 month period. ${ }^{26}$ In 2013 Lanzafameet al reported an increase in hair counts of 41 male patients ( 22 active and 19 placebo) with androgenetic alopecia using TOPHAT655 for 25 minutes at home every other day for 16 weeks. TOPHAT655 used by patients at home contained 21piece $5 \mathrm{~mW} 655 \mathrm{~nm}$ lasers and 30 piece LED $655 \mathrm{~nm}$ lasers. ${ }^{27}$

In 2007, US Food and Drug administration (FDA) approved Hairmax Lasercomb for male pattern hair loss treatment and in 2011 approved it for female pattern hair loss treatment. ${ }^{28}$ Zareiet al reviewed the FDA cleared LLLT devices, and concluded that thee devices did not have adverse effects and were effective for both AAI and FPHL. ${ }^{29}$ van Zuurenet al did an extensive literature review, and concluded that LLLT devices show some efficacy in FPHL by increasing hair count, however, the studies thus far have moderate to low quality evidence.$^{30}$ However, Gupta et al compared none trials on LLLT for hair loss and concluded that the weakness of the evidence hindered a conclusive result. ${ }^{31}$ Afifi et al, conducted a systematic review of the data from 1960 to 2015, with risk of bias assessment; they concluded that LLLT is a cautiously promising monotherapy for AAI. ${ }^{32}$ Other systematic reviews corroborated the conclusion. ${ }^{33,34}$

\section{ConClusion}

There are many studies that support the efficacy of LLLT for AAI and FPHL. However, the power of the studies is low, as pointed out by Gupta and Daigle. ${ }^{35}$ Dodd et al reminds us that to date there have not been any head-to-head comparison of the different LLLT devices for AAI or FPHL. ${ }^{36}$ There have been a few systematic reviews of the current literature which indicate LLLT efficacy for AAI and FPHL. Larger number studies are needed for stronger evidence and greater power. 
Low Level Laser Treatment for Patterned Hair Loss: Is it Effective?

\section{REFERENCES}

[1] Manabe M, Tsuboi R, Itami S, Osada S-I. Guidelines for the diagnosis and treatment of male-pattern and female-pattern hair loss, 2017 version. J Derrmatology. 2018; 45(9):1031-1043. https:// doi.org/10.1111/1346-8138.14470

[2] Hamilton JB. Male pattern hair loss in man: types and incidence. Ann N Y Acad Sci. 1951; 53: 708-728.

[3] Birch MP, Messenger JF, Messenger AG. Hair density, hair diameter and the prevalence of female pattern hair loss. Br J Dermatol. 2001; 144:297-304.

[4] Vujovic A, Del Marmol V. The Female Pattern Hair Loss: Review of Etiopathogenesis and Diagnosis. Biomed Res Int. 2014; 2014: 767628.

[5] Huang YY, Sharma SK, Carroll J, Hamblin MR. Biphasic Dose Response in Low Level Light Therapy-An Update. Dose Response. 2009; 7: 358-383.

[6] Jimenez JJ, Wikramanayanke TC, Bergfeld W et al. Efficacy and Safety of a Low Level Laser Device in the treatment of Male and Female Pattern Hair loss: A Multicenter, Randomized, Sham Device Controlled, Double Blind Study. Am J Clin Dermatol 2014; 15: 115-127.

[7] Mester E, Szende B, Gartner P. The effect of laser beams on the growth of hair in mice. RadiobiolRadiother 1968:9:621-626.

[8] Anderson RR, Parrish JA. Selective Photothermolysis: Precise microsurgery by selective absorption of pulse radiation. Science. 1983; 220: 524.

[9] Grossman MC, Dierick CC, Farinelli WA, Flotte TJ, Anderson RR. Damage to hair follicles by normal mode ruby laser pulses. J Am Acad Dermatol. 1996; 35: 889.

[10] Moreno-Arias GA, Castelo-Cranco C, Ferrando J. Side Effects After IPL Photoepilation. Derm Surg. 2002; 12:1131-1134. https://doi.org/10.1046/ j.1524-4725.2002.02117.x

[11] Lolis M, Marmur E, Marmur BS. Paradoxical Effects of Hair Removal Systems: A Review. J Cosmet Dermatol. 2006; 5:274-6.

[12] Bedewi A. Hair Removal with Intense Pulsed Light. Lasers Med Sci 2004; 19: 48-55
[13] Desai S, Mahmoud BH, Bhatia AC, Hamzavi IH. Paradoxical Hypertrichosis After Laser Therapy: A Review. Dermatol Surg. 2010; 36: 291-8.

[14] Alajlan A, Shapiro J, Rivers J, MacDonald N, Wiggin J, Lui H. Paradoxical hypertrichosis after laser epilation. J Am Acad Dermatol 2005; 53: 85-8.

[15] Levy V, Lindon C, Zheng Y, Harfe BD, Morgan BA. Epidermal stem cells arise from the hair follicle after wounding. FASEB J. 2007; 21:1358-66.

[16] Kim Won-Serk, Lee HI, Lee WJ, et al. Fractional Photothermolysis laser treatment of male pattern hair loss. Fractional Photothermolysis laser treatment of male pattern hair loss. Dermatol Surg. 2011 Jan; 37(1):41-51.

[17] Greco M, Guida G, Perlino E et al. Increase in RNA and Protein Synthesis by Mitochondria Irradiated with Helium Neon Laser. BiochemBiophys Res Commun. 1989 Sep 29; 163(3): 1428-34.

[18] Passarella S, Casamassima E, Molinari S, Pastore D etal. Increase of Proton Electrochemical Potential and ATP Synthesis in Rat Liver Mitochondria Irradiated in Vitro by Helium-Neon Laser. FEBS Lett. 1984 Sep 17; 175(1):95-9.

[19] Lubart R, Eichler M, Lavi R, Friedman H, Shainberg A. Low-energy laser irradiation promotes cellular redox activity. Photomed Laser Surg. 2005 Feb; 23(1):3-9.

[20] Antunes F, Boveris A, Cadenas E. On the mechanism and biology of cytochrome oxidase inhibition by nitric oxide. Proc Natl Acad Sci USA. 2004; 101: 16774-16779.

[21] Nicole L Lohr, Agnes Keszler, Phillip Pratt et al. Enhancement of Nitric Oxide Release from Nitrosyl Hemoglobin and Nitrosyl Myoglobin by Red/Near Infrared Radiation: Potential Role in Cardio protection. J Mol Cell Cardiol. 2009 Aug; 47(2): 256-263.

[22] Bouzari N, Firooz AR. Lasers may induce terminal hair growth. Dermatol Surg 2006; 10: 96-8.

[23] Weiss R, McDaniel DH, Geronemus RG et al. LowLevel Laser (Light) Therapy (LLLT) for Treatment of Hair Loss. 2014; 46(20:144-151. DOI 10.1002/ lsm. 22170

[24] Avci P, Gupta GK, Clark J, et al. Low-Level Laser (Light) Therapy (LLLT) for Treatment of Hair Loss. 
Low Level Laser Treatment for Patterned Hair Loss: Is it Effective?

[25] Orasan MS, Coneac A, Mihu CM, Mare C, Muresan A. Minoxidil and Neoptidetopical application reinforced by Low Level laser therapy on an animal model ofalopecia. StudiaChemia UBB. 2015; 60(2):295-308.

[26] Satino JL, Markou M. Hair Regrowth and Increased Hair Tensile Strength Using the HairMaxLaserComb for Low-Level Laser Therapy. International Journal of Cosmetic Surgery and Aesthetic Dermatology. 2003; 5(2):113-117

[27] Lanzafame RJ, Blanche RR, Bodian AB et al. The growth of human scalp hair mediated by visible redlight laser and LED sources in males. Lasers Surg Med. 2013; 45:487-95. doi: 10.1002/ lsm. 22173

[28] Hession MT, Markova A, Graber EM. A Review of Hand-Held, Home-Use Cosmetic Laser and Light Devices. Dermatol Surg 2015; 41; 307-320. Lasers Surg Med. 2014 Feb; 46(2): 144-151.doi: 10.1002/lsm.22170

[29] Zarei M, Wikramanayake TC, Falto-Aizpurua L, Schachner LA, Jimenez JJ.Low level laser therapy and hair regrowth: an evidence-based review. Lasers Med Sci. 2016 Feb;31(2):363-71. doi: $10.1007 / \mathrm{s} 10103-015-1818-2$

[30] van Zuuren EJ, Fedorowicz Z, Schoones J.Interventions for female pattern hair loss. Cochrane Database Syst Rev. 2016 May 26;(5):CD007628. doi: 10.1002/14651858. CD007628.pub4.
[31] Gupta AK, Foley KA.A Critical Assessment of the Evidence for Low-Level Laser Therapy in the Treatment of Hair Loss.Dermatol Surg. 2017 Feb;43(2):188-197. doi: 10.1097/ DSS.0000000000000904.

[32] Afifi L, Maranda EL, Zarei M, Delcanto GM, FaltoAizpurua L, Kluijfhout WP, Jimenez JJ.Low-level laser therapy as a treatment for androgenetic alopecia.Lasers Surg Med. 2017 Jan;49(1):27-39. doi: $10.1002 /$ lsm.22512.

[33] Najem I, Chen H. Use of low-level laser therapy in treatment of the androgenic alopecia, the first systematic review. J Cosmetic and Laser Therapy. 2018;20:252-257.https://doi.org/10.1080/147 64172.2017 .1400174

[34] Delaney SW, Zhang P. Systematic review of lowlevel laser therapy for adult androgenic alopecia. J Cosmetic and Laser Therapy. 2018; 4:229-236. https://doi.org/10.1080/14764172.2017.1400170.

[35] Gupta AK, Daigle D.The use of low-level light therapy in the treatment of androgenetic alopecia and female pattern hair loss.J Dermatolog Treat. 2014 Apr;25(2):162-3. doi: $10.3109 / 09546634.2013 .832134$

[36] Dodd EM, Wintere MA, et al. Photobiomodulation therapy for androgenetic alopecia: A clinician's guide to home-use devices cleared by the Federal Drug Administration. J Cosmetic and Laser Therapy. 2018; 20:159-167.

Citation: Omeed Memar, Benjamin Caughlin, Hamid Djalilian. Low Level Laser Treatment for Patterned Hair Loss: Is it Effective?. Archives of Dermatology and Skin Care. 2018; 1(2): 20-24.

Copyright: (c) 2018 Omeed Memar, Benjamin Caughlin, Hamid Djalilian. This is an open access article distributed under the Creative Commons Attribution License, which permits unrestricted use, distribution, and reproduction in any medium, provided the original work is properly cited. 